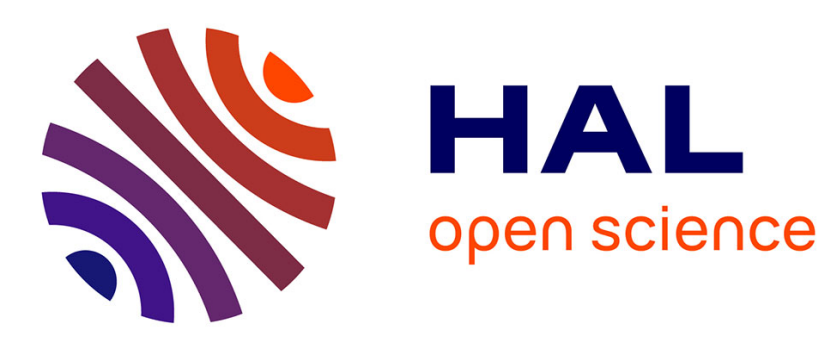

\title{
Interoperability Assessment in the Deployment of Technical Processes in Industry
}

Clémentine Cornu, Vincent Chapurlat, Jean-Marc Quiot, François Irigoin

\section{To cite this version:}

Clémentine Cornu, Vincent Chapurlat, Jean-Marc Quiot, François Irigoin. Interoperability Assessment in the Deployment of Technical Processes in Industry. INCOM 2012, The 14th edition of IFAC's triennal symposium INCOM, May 2012, Bucharest, Romania. pp. F20-F25. hal-00750860

\section{HAL Id: hal-00750860}

https://hal-mines-paristech.archives-ouvertes.fr/hal-00750860

Submitted on 12 Nov 2012

HAL is a multi-disciplinary open access archive for the deposit and dissemination of scientific research documents, whether they are published or not. The documents may come from teaching and research institutions in France or abroad, or from public or private research centers.
L'archive ouverte pluridisciplinaire HAL, est destinée au dépôt et à la diffusion de documents scientifiques de niveau recherche, publiés ou non, émanant des établissements d'enseignement et de recherche français ou étrangers, des laboratoires publics ou privés. 


\title{
Interoperability Assessment in the Deployment of Technical Processes in Industry
}

\author{
Clémentine Cornu*, Vincent Chapurlat**, Jean-Marc Quiot*, and François Irigoin*** \\ * Eurocopter, ETZR, Aéroport International Marseille Provence 13725 Marignane Cedex - France \\ (e-mail: \{Clementine.Cornu ; Jean-Marc.Quiot\}@eurocopter.com) \\ ** LGI2P - Site EERIE de l'EMA, Parc Scientifique George Besse 30035 Nîmes cedex 1 - France \\ (e-mail: Vincent.Chapurlat@mines-ales.fr) \\ *** Mines ParisTech - CRI, 35 rue Saint Honoré, 77305 Fontainebleau Cedex - France \\ (e-mail: François.Irigoin@mines-paristech.fr)
}

\begin{abstract}
Increasing competition on markets induces a vital need for companies to improve their efficiency and reactivity. For this, a solution is to deploy, improve and manage their processes while paying a special attention on the abilities of the resources involved. Particularly, the interoperability of the latter is considered in this article as a challenge conditioning the success of the deployment. Consequently, this paper presents a mean to assess interoperability of the resources involved in a process during all its life cycle.
\end{abstract}

Keywords: Interoperability Assessment, Process, Enterprise Systems Engineering

\section{INTRODUCTION}

The deployment of new processes in a company is a strategic decision consisting in the addition or modification of activities considered as required and relevant to the business strategy. This deployment can be divided into three stages: 1) a pre-deployment stage including planning and analysis; 2) a stage of practical and effective implementation, and 3) a postdeployment stage including process management and continuous improvement. The first phase mainly aims to determine what activities should be implemented or adapted considering the defined but shifting strategic objectives. Then, the second phase of practical implementation is the most delicate stage considering all obstacles of different nature (human, technical, organizational, etc.) to overcome. In this paper, we assume that they are linked to difficulties of collaboration (i.e. difficulties to be interoperable) at all levels of the organization. Finally the third stage consists in implementing a system in charge of managing the deployed processes. It aims to preserve and improve the profitability of these processes taking into account the needs of their stakeholders. It also aims to ensure that new processes do not endanger the stability and integrity of the organization but conversely improve them. In this paper, we assume that some of these management activities are not effective if the interoperability of the organization is here again not controlled.

Consequently, when deploying new processes in large companies, it appears necessary to get a method to improve interoperability. One is included in a methodological guide for the deployment of Systems Engineering processes detailed in (Cornu et al., 2011). This paper describes the principles of a method we recommend to assess the interoperability of entities i.e. resources and business units likely to be involved in a process to deploy.

\section{FRAMEWORK FOR THE ASSESSMENT}

This section aims to define the framework in which the interoperability assessment should be conducted. It describes the types of assessments we need in the deployment of processes and their targets.

\subsection{Interoperability Assessment Matrix}

Interoperability can be defined as the "ability of companies and entities within those companies to communicate and interact effectively" (ISO, 2010). In order to guide its assessment, we have defined an Interoperability Assessment Matrix (see Table 1).

Table 1. Interoperability Assessment Matrix.

\begin{tabular}{|c|c|c|c|}
\hline & \multicolumn{2}{|c|}{ Object of the assessment } \\
\hline & & $\begin{array}{c}\text { Intrinsic } \\
\text { interoperability } \\
\text { Only one entity is } \\
\text { considered }\end{array}$ & $\begin{array}{c}\text { Extrinsic } \\
\text { interoperability } \\
\text { A couple of entities is } \\
\text { considered }\end{array}$ \\
\hline 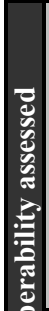 & $\begin{array}{c}\text { Potential } \\
\text { interoperability } \\
\text { Before } \\
\text { collaboration }\end{array}$ & $\begin{array}{l}\text { The purpose here is to } \\
\text { evaluate the ability of } \\
\text { the entity to } \\
\text { interoperate with any } \\
\text { partner. The partner is } \\
\text { not known. }\end{array}$ & $\begin{array}{l}\text { The purpose here is to } \\
\text { evaluate the future } \\
\text { interoperability of the } \\
\text { couple during a } \\
\text { collaboration. } \\
\text { The partners know each } \\
\text { other but have not } \\
\text { started a collaboration } \\
\text { yet. }\end{array}$ \\
\hline 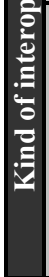 & $\begin{array}{c}\text { Effective } \\
\text { interoperability } \\
\text { During or after } \\
\text { collaboration }\end{array}$ & $\begin{array}{l}\text { The purpose here is to } \\
\text { evaluate the effective } \\
\text { ability of the entity to } \\
\text { interoperate with a } \\
\text { partner. The partner is } \\
\text { known but only the } \\
\text { interoperability of one } \\
\text { entity is assessed. }\end{array}$ & $\begin{array}{l}\text { The purpose here is to } \\
\text { evaluate the effective } \\
\text { interoperability of the } \\
\text { couple during their } \\
\text { collaboration. The } \\
\text { partners know each } \\
\text { other and interact. }\end{array}$ \\
\hline
\end{tabular}


The first dimension of this matrix concerns the object of the assessment and is based on the distinction between intrinsic and extrinsic interoperability proposed by (Daclin, 2007). On one hand, "extrinsic interoperability" refers to the characteristic of a couple of entities to efficiently collaborate together, whereas "intrinsic interoperability" only focuses on abilities of a single resource. The second dimension concerns the moment of the assessment (Ibid.). On one hand, if the assessment is done before any collaboration we talk about "potential interoperability" whereas if the assessment is done once the collaboration has started or is complete, we talk about "effective interoperability".

The four cells of the matrix represent possible types of assessment. In the context of process deployment, we need the four of them. Indeed, before the deployment, we need to identify the current difficulties in collaborations. After the deployment, it is relevant to perceive progress achieved. These appraisals should be done on both single and couples of systems. Therefore, effective extrinsic/intrinsic interoperability assessments are required. Besides, if new resources are considered to take part in the new process, the deployment team needs to ensure that they have abilities to collaborate with other resources in the frame of the given process but also that collaborations with current and new resources will be efficient. Therefore, potential extrinsic/intrinsic Interoperability assessments are required.

Thus, we identified assessments types based on two of interoperability characterizations. However some additional questions should be answered. First, the distinction between intrinsic and extrinsic interoperability is based on the notion of "entities", but can we define generic types of entities to facilitate the evaluation of their interoperability? Second, the distinction between potential and effective interoperability is based on the notion of collaboration. Then, considering the categorization of entities, can we identify generic categories of collaborations to facilitate, here again, the interoperability appraisal? The following sub-section answers to these questions.

\subsection{Characterisation of assessment targets}

To identify entities that could be involved in all collaborations of a company, we adopted the principle of systematism: everything can be considered as a system. We have thus identified three kinds of systems (see Figure 1):

- Human Systems. They are constituted by a single person or a group of people (e.g. team).

- Non-Human Systems. They are constituted by anything that is not a human being (e.g. computer, machine, etc.).

- Heterogeneous group of systems. They are constituted by both human and non-systems (company, department, etc.)

We have then assumed that it is easier to examine the interoperability of each company's elements separately and then as a whole in order to determine the interoperability of this company. We have thus identified the interactions shown on Figure 1 and developed assessment methods in the context of all these interactions but those between Heterogeneous group of systems and Human Systems/Non-Human Systems.
Indeed, we do not think that these interactions are relevant since they can finally be reduced to Human Systems interactions.

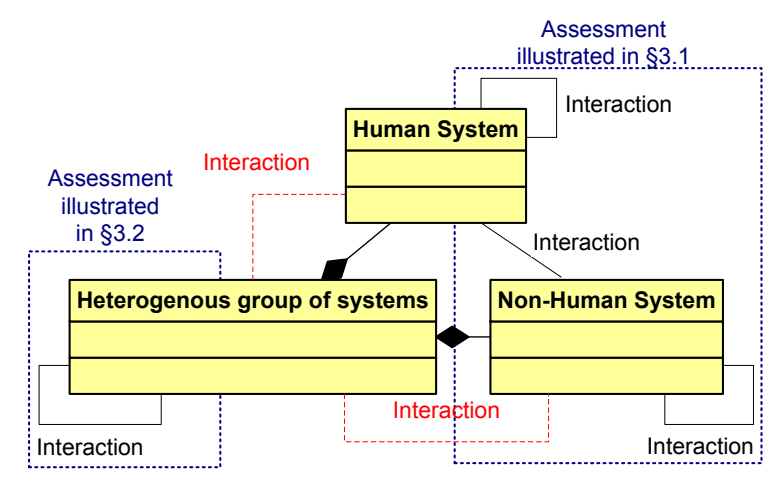

Fig. 1. Types of collaborating systems and interactions

This sub-section introduces a framework for interoperability assessment. But it is "empty" and should be completed with methodological tools providing practical means for appraisal. They are presented in the next section.

\section{PRINCIPLES AND ILLUSTRATIONS OF PROPOSED ASSESSMENT METHOD}

To assess resources during collaboration we have identified above, existing contributions designed for appraisal can be used. For instance:

- For potential intrinsic interoperability assessment: (ATHENA, 2005), (Guédria et al., 2009), (Kingston et al., 2005),(NEHTA, 2007),(Soria et al., 2009), and (Daclin, 2007).

- For potential extrinsic interoperability assessment: (Tolk and Muguira, 2003) and (Daclin, 2007).

- For effective intrinsic interoperability assessment: (Guédria et al., 2009), (Hamilton et al., 2002), (Kingston et al., 2005), (NEHTA, 2007), (Soria et al., 2009) and (Daclin, 2007).

- For effective extrinsic interoperability assessment: (Clark and Jones, 1999), (Ford et al., 2007), (Hill, 2006), (IEC, 2005), (Leite, 1998), (Lavean, 1980), (C4ISR, 1998), (Santos et al., 2008), (Stewart et al., 2004), (Tolk and Muguira, 2003) and (Daclin, 2007).

However, to our knowledge, none of them addresses the four cells of Table 1. In addition, the three traditional barriers to interoperability (conceptual, organizational and technical) (ISO, 2010) are not necessarily all taken into account. So, we propose a new evaluation method taking into account all these points and aiming to be directly and easily applicable in industry. For each interaction identified on Figure 1, interoperability assessment protocols are proposed. The assessor picks among the nine available the one applicable according to the type of interoperability and resource concerned. Four of them are illustrated in the following subsections. All defined protocols are provided with recommendations to improve interoperability and a clear identification of interoperability barriers they aim to remove but they are not presented here to save space. 


\subsection{Assessment of components constituting organisations}

This sub-section aims to illustrate how to assess systems constituting an organisation. The protocol shown here exemplifies the appraisal of a Non-Human System alone or in collaboration with a Human System.

\section{Extrinsic interoperability assessment}

To assess extrinsic interoperability, a set of questions is proposed according to the type (potential/effective) of assessment desired. The person in charge of the assessment starts with the first question, provides an answer, and follows instructions provided. While he/she is invited to go to next question, the assessment goes on. However, when a "case End" is reached, the assessment is over and the result is provided by variable "S" (see Figure 3 for an example).

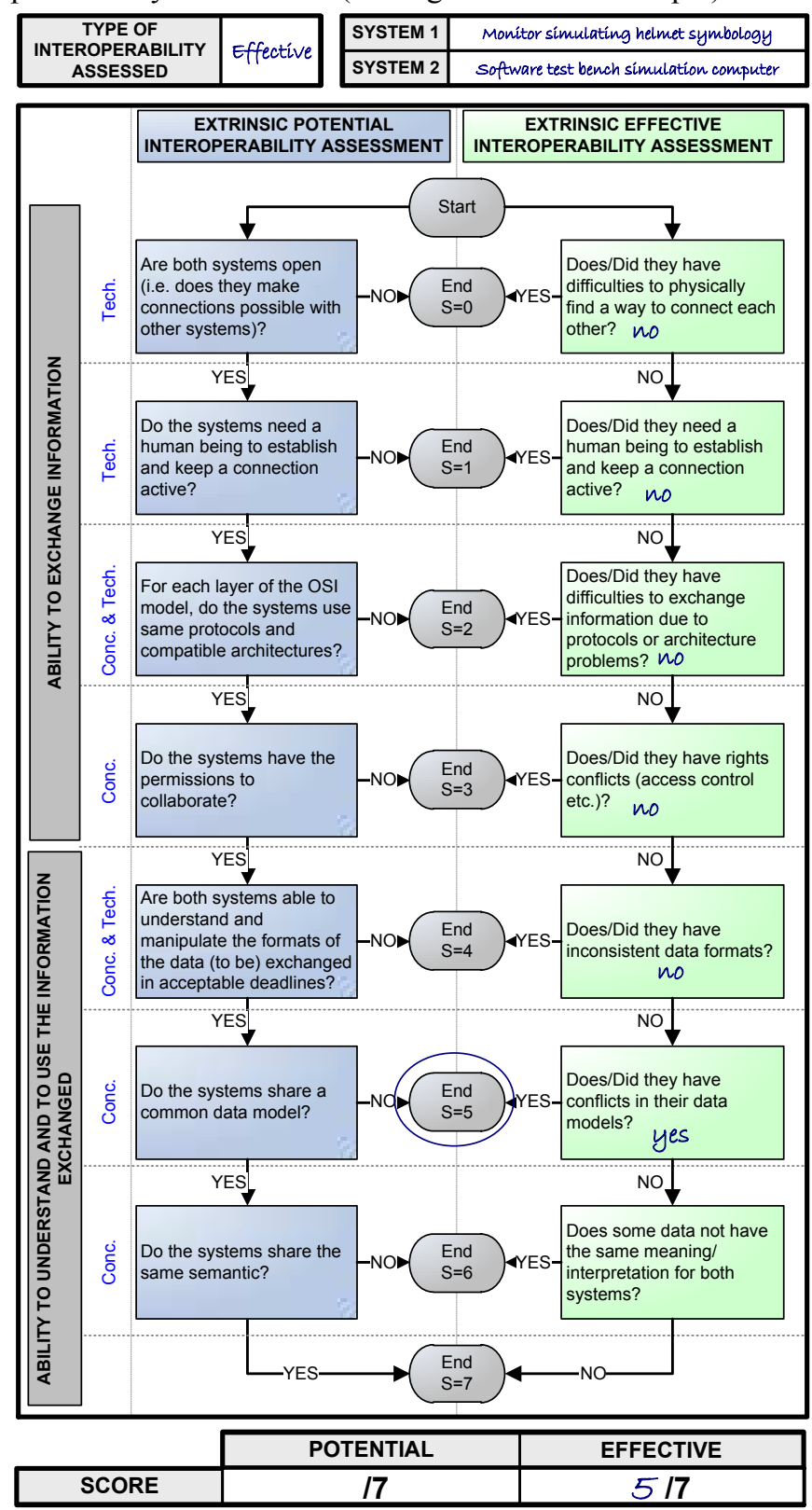

Fig. 2. Non-human systems effective extrinsic interoperability assessment

\section{Intrinsic interoperability assessment}

To assess intrinsic interoperability, a set of questions is asked according to the type (potential/effective) assessed. Unlike the extrinsic interoperability assessment, all questions should be answered (i.e. a "NO" does not stop the assessment) and the sum of all "YES" gives the score. Figure 4 provides an example for the assessment of potential interoperability of a Non-Human System.

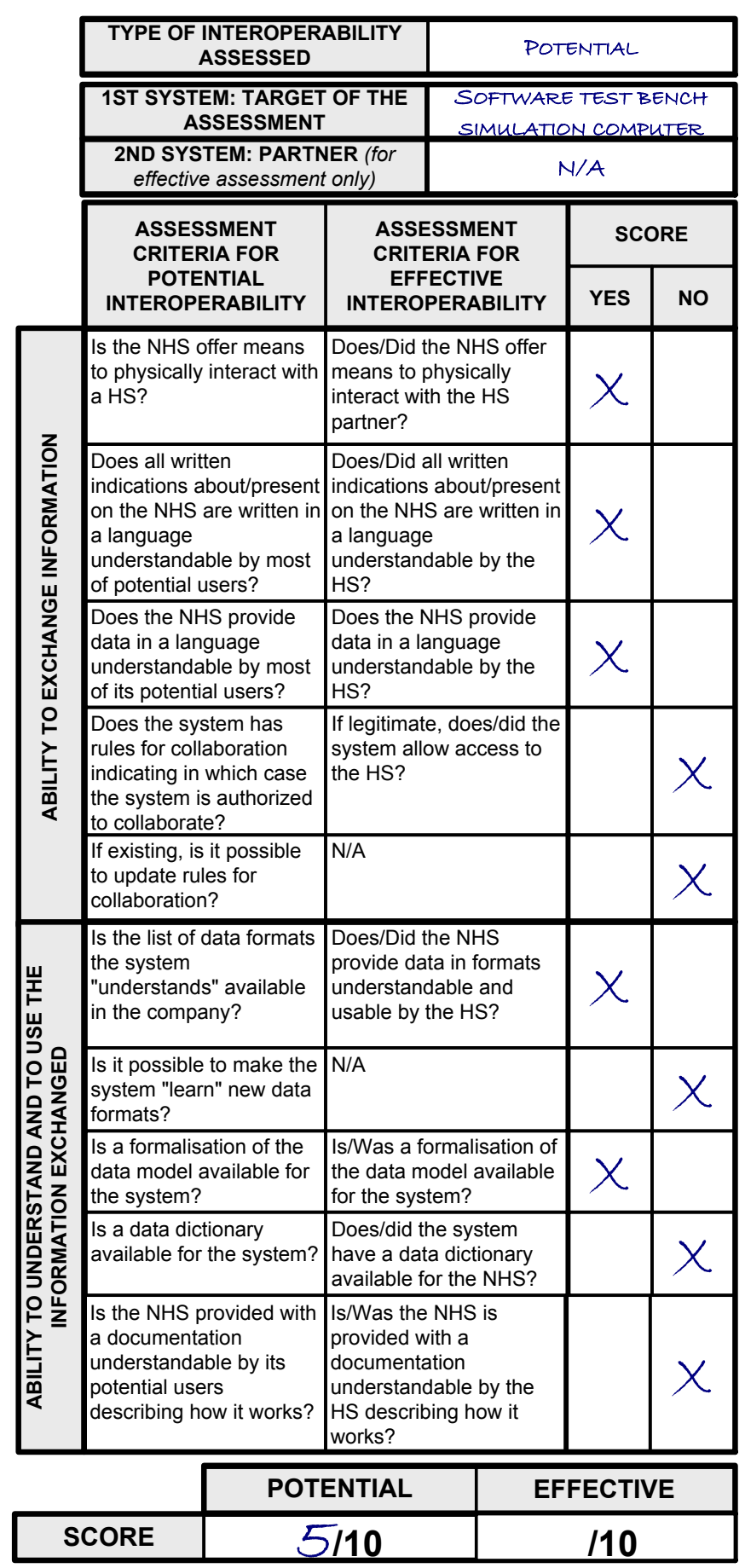

Fig 3. Non-human systems (NHS) potential intrinsic interoperability assessment 


\subsection{Global assessment of organisations}

This sub-section aims to illustrate principles of assessment methods for extrinsic and intrinsic interoperability of organisations (companies, departments, etc.) considered as a whole.

Extrinsic (potential \& effective) interoperability assessment

This assessment is conditioned by the type of interoperability assessed (potential/effective) and consists in three steps. The first one aims to calculate a score S1 according to a flow chart illustrated on Figure 4 for an effective interoperability assessment.

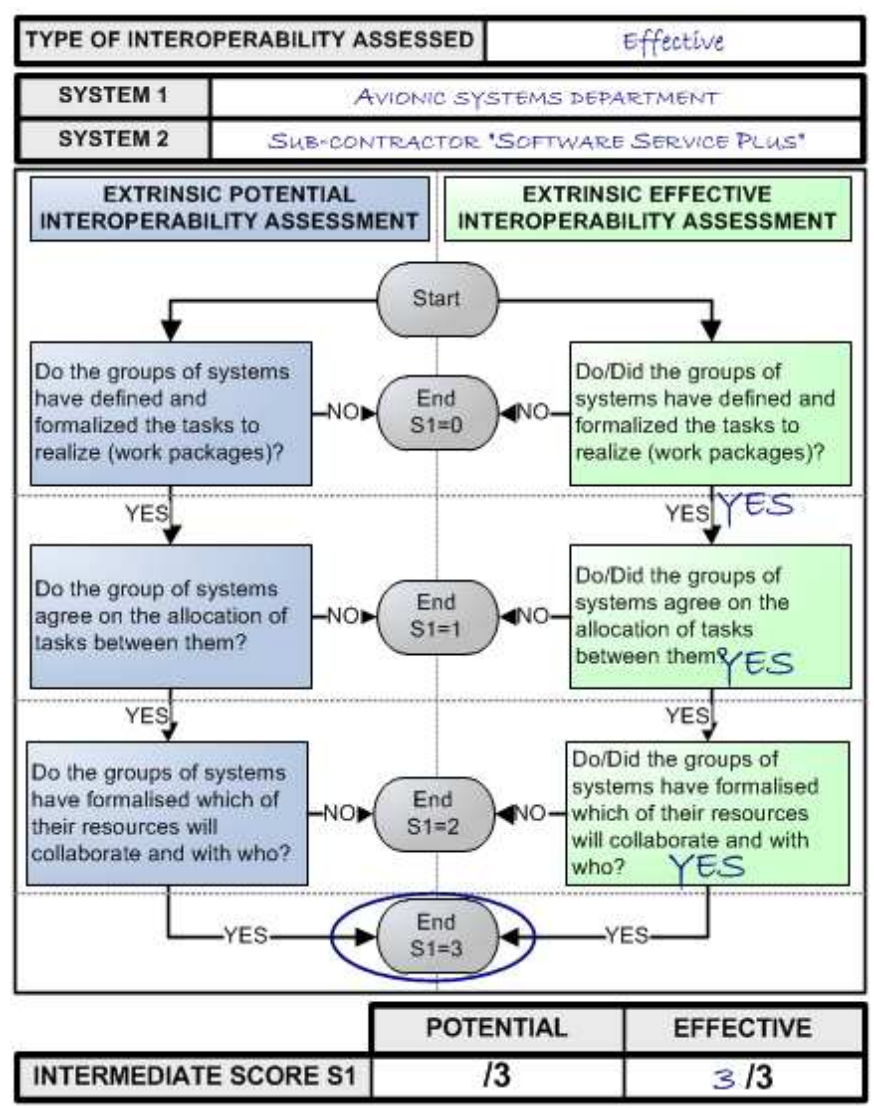

Fig. 4. First step of the effective extrinsic interoperability assessment of heterogeneous group of systems

Then, the score S1 must be improved until it reaches 3, i.e. until all couples of systems having to collaborate have been identified. Then extrinsic interoperability score of each couple identified should be assessed with methods presented in Sub-section 3.1.

Finally, the last step is performed: the calculus of the final score S2 according to Table 2. For our example, if three couples have been identified and got the following results:

$\mathrm{I}_{\mathrm{E}}{ }^{\mathrm{e}}\left(\mathrm{C}_{1}\right)=5 / 7, \mathrm{I}_{\mathrm{E}}{ }^{\mathrm{e}}\left(\mathrm{C}_{2}\right)=4 / 8$, and $\mathrm{I}_{\mathrm{E}}{ }^{\mathrm{e}}\left(\mathrm{C}_{3}\right)=1 / 5$; then final result is $\mathrm{S} 2=5 / 7+4 / 8+1 / 5=1,4143$.
Table 2. Formulas for heterogeneous extrinsic interoperability assessment

\begin{tabular}{|c|c|c|}
\cline { 2 - 3 } \multicolumn{1}{c|}{} & POTENTIAL & EFFECTIVE \\
\hline FORMULA SCORE S2 & $\sum_{\mathrm{i}=1}^{\mathrm{i}=\mathrm{n}}\left(\mathrm{I}_{\mathrm{E}}^{\mathrm{p}}\left(\mathrm{C}_{\mathrm{i}}\right)\right)$ & $\sum_{\mathrm{i}=1}^{\mathrm{i}=\mathrm{n}}\left(\mathrm{I}_{\mathrm{E}}^{\mathrm{e}}\left(\mathrm{C}_{\mathrm{i}}\right)\right)$ \\
\hline MAXIMAL SCORE S2 & $\sum_{\mathrm{i}=1}^{\mathrm{i}=\mathrm{n}}\left(\operatorname{Max}\left(\mathrm{I}_{\mathrm{E}}^{\mathrm{p}}\left(\mathrm{C}_{\mathrm{i}}\right)\right)\right)$ & $\sum_{\mathrm{i}=1}^{\mathrm{i}=\mathrm{n}}\left(\operatorname{Max}\left(\mathrm{I}_{\mathrm{E}}^{\mathrm{e}}\left(\mathrm{C}_{\mathrm{i}}\right)\right)\right)$ \\
\hline
\end{tabular}

With:

- $\mathrm{n}=$ number of collaborating couple of resources belonging to the two organisations

- $\mathrm{C}_{\mathrm{i}}=$ couple \#i

- $\mathrm{I}_{\mathrm{E}}^{\mathrm{p}}\left(\mathrm{C}_{\mathrm{i}}\right)=$ Result of the extrinsic potential interoperability assessment of the couple $\mathrm{C}_{\mathrm{i}}$

- $\mathrm{I}_{\mathrm{E}}{ }^{\mathrm{e}}\left(\mathrm{C}_{\mathrm{i}}\right)=$ Result of the extrinsic effective interoperability assessment of the couple $\mathrm{C}_{\mathrm{i}}$

\section{Intrinsic (potential \& effective) interoperability assessment}

Just like extrinsic assessment, the type of interoperability (potential/effective) conditions the appraisal consisting in three steps. The first one calculates a score S1 according to results of questions addressing the organisation assessed from a global point of view. This step is illustrated in Figure 5 using the same example as for extrinsic interoperability assessment.

\begin{tabular}{|c|c|c|c|}
\hline \multirow{2}{*}{$\begin{array}{c}\text { ASSESSMENT CRITERIA } \\
\text { FOR POTENTIAL } \\
\text { INTEROPERABILITY }\end{array}$} & \multicolumn{2}{|c|}{ SCORE } & \multirow{2}{*}{$\begin{array}{l}\text { INTEROP. } \\
\text { BARRIERS) } \\
\text { CONCERNED }\end{array}$} \\
\hline & YES & NO & \\
\hline $\begin{array}{l}\text { Does the group of systems } \\
\text { has an up-to-date reliable } \\
\text { formalisation of its } \\
\text { processes? }\end{array}$ & & & Organisationa \\
\hline $\begin{array}{l}\text { Does the group of systems } \\
\text { has an up-to-date reliable } \\
\text { formalisation of its } \\
\text { resources (skills, etc.)? }\end{array}$ & & & Organisational \\
\hline \multirow{2}{*}{$\begin{array}{l}\text { ASSESSMENT CRITERIA } \\
\text { FOR EFFECTIVE } \\
\text { INTEROPERABILITY }\end{array}$} & \multicolumn{2}{|c|}{ SCORE } & INTEROP. \\
\hline & YES & NO & CONCERNED \\
\hline $\begin{array}{l}\text { Does/Did the group of } \\
\text { systems not have difficulties } \\
\text { to identify tasks it can } \\
\text { perform? }\end{array}$ & & & Organisationa \\
\hline \multirow{2}{*}{$\begin{array}{l}\text { Does/Did the group of } \\
\text { systems not have difficulties } \\
\text { to identify resources to get } \\
\text { involved in collaborations? }\end{array}$} & & & Organisational \\
\hline & \multicolumn{2}{|c|}{ POTENTIAL } & EFFECTIVE \\
\hline SCORE S1 & \multicolumn{2}{|c|}{12} & $0 / 2$ \\
\hline
\end{tabular}

Fig. 5. First step of effective intrinsic interoperability assessment of heterogeneous group of systems 
Then, individual assessment of resources should be conducted. For potential interoperability, by default, all the resources of the group of systems are assessed except if a smaller assessment boundary can be defined. For effective interoperability, only resources involved in collaborations are assessed. If a resource is involved in different collaborations, extrinsic interoperability assessment must be done for each collaboration defined.

Finally, total score should be calculated according to Table 3. Considering our example, if results for the six resources identified are: $\mathrm{I}_{\mathrm{I}}^{\mathrm{e}}\left(\mathrm{R}_{1}\right)=2 / 7, \mathrm{I}_{\mathrm{I}}^{\mathrm{e}}\left(\mathrm{R}_{2}\right)=4 / 8, \mathrm{I}_{\mathrm{I}}^{\mathrm{e}}\left(\mathrm{R}_{3}\right)=1 / 5, \mathrm{I}_{\mathrm{I}}^{\mathrm{e}}$ $\left(\mathrm{R}_{4}\right)=5 / 5, \mathrm{I}_{\mathrm{I}}^{\mathrm{e}}\left(\mathrm{R}_{5}\right)=4 / 5, \mathrm{I}_{\mathrm{I}}^{\mathrm{e}}\left(\mathrm{R}_{6}\right)=1 / 5$; then final score is: $\mathrm{S} 2=2 / 7+4 / 8+1 / 5+5 / 5+4 / 5+1 / 5=2,9857$.

\begin{tabular}{|c|c|c|}
\hline \multicolumn{3}{|c|}{$\begin{array}{l}\text { Table 3. Formula for heterogeneous intrinsic } \\
\text { interoperability assessment }\end{array}$} \\
\hline & POTENTIAL & EFFECTIVE \\
\hline FORMULA SCORE S2 & $\sum_{\mathrm{i}=1}^{\mathrm{i}=\mathrm{n}}\left(\mathrm{I}_{\mathrm{I}}^{\mathrm{p}}\left(\mathrm{R}_{\mathrm{i}}\right)\right)$ & $\sum_{\mathrm{i}=1}^{\mathrm{i}=\mathrm{n}}\left(\mathrm{I}_{\mathrm{I}}^{\mathrm{e}}\left(\mathrm{R}_{\mathrm{i}}\right)\right)$ \\
\hline MAXIMAL SCORE S2 & $\sum_{\mathrm{i}=1}^{\mathrm{i}=\mathrm{n}}\left(\operatorname{Max}\left(\mathrm{I}_{\mathrm{I}}^{\mathrm{p}}\left(\mathrm{R}_{\mathrm{i}}\right)\right)\right)$ & $\sum_{\mathrm{i}=1}^{\mathrm{i}=\mathrm{n}}\left(\operatorname{Max}\left(\mathrm{I}_{\mathrm{I}}^{\mathrm{e}}\left(\mathrm{R}_{\mathrm{i}}\right)\right)\right)$ \\
\hline \multicolumn{3}{|c|}{$\begin{array}{l}\text { With: } \\
\text { - } \quad n=\text { number of resources to assess } \\
\text { - } R_{i}=\text { resource } \# i \\
I_{I}^{p}\left(R_{i}\right)=\text { Result of the intrinsic potential interoperability } \\
\text { assessment of the resource } R_{i} \\
I_{I}^{e}\left(R_{i}\right)=\text { Result of the intrinsic effective interoperability } \\
\text { assessment of the resource } R_{i}\end{array}$} \\
\hline
\end{tabular}

Thus, this section has illustrated the different methods we propose to evaluate interoperability in an industrial context. However, these methods handle a lot of concepts and it seems relevant to define them formally to facilitate and restrict their application. For this, a meta-model presented in next section is proposed.

\section{META-MODEL OF INTEROPERABILITY ASSESSMENT METHOD}

During the deployment of a process, lots of people may have to manage interoperability assessment activities for each resource involved or potentially involved in the concerned process. Therefore, everything must be done to help them understand each other to limit misunderstanding and thus conflicts. To that end, a meta-model is proposed (see Figure 6). Its purpose is to define all concepts and relations between them that are used during the assessment but also during result analyses. For each concept and each relation, a definition in natural language is provided to guide the assessor. The guiding approach and the details of this metamodel are not presented in this article.

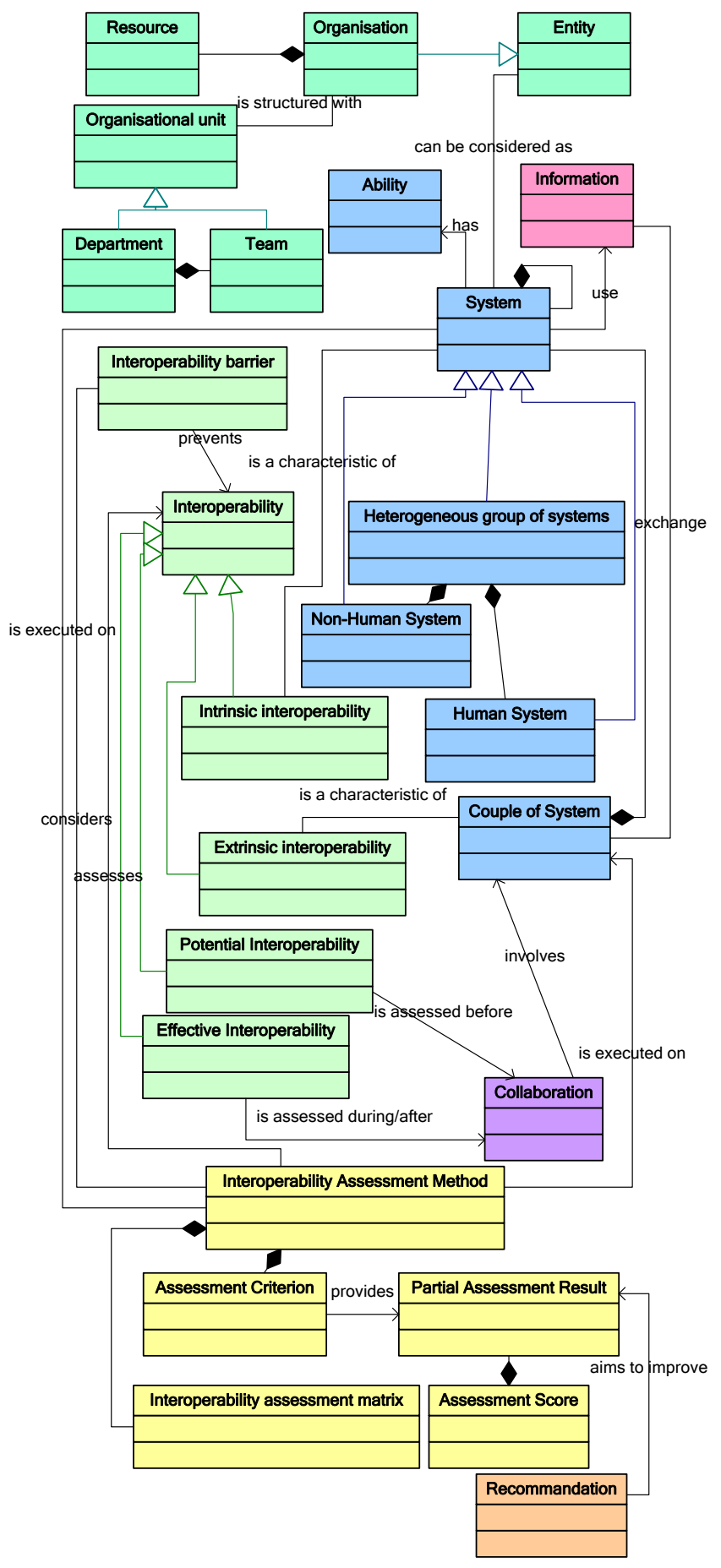

Fig. 6. Simplified meta-model of the interoperability method

\section{CONCLUSION}

Interoperability is a condition of success for process deployment in companies. It should be assessed all along deployment stages. To that end, this paper presents the principles of a method to assess interoperability of resources involved or potentially involved in processes. It can be applied on single or couples of resources and is applicable not only once the collaboration has started but also before a collaboration to anticipate future difficulties. 
This assessment method is useful before and after the pragmatic deployment.

On one hand, during the preparation of the deployment we may use it for three kinds of application. Firstly it can be used as a camera that enables taking an initial picture of the entity in preparation for deployment efficiency assessment. Besides it enables highlighting interoperability problems to find clues about where new processes should provide improvements. Secondly, this method can be used as a guide for resource allocation. Indeed, it is a mean to choose between two apparently equivalent resources and it enables checking if resources we plan to allocate to the new processes are able to work together. Thirdly, it can be used as a guide to improve interoperability abilities of resources or entities before the deployment to maximize its chances of success.

On the other hand, the interoperability assessment method can be a real advantage once processes have been deployed and are operational. Indeed, it can be used as a verification tool that enables not only checking that resources we have planed to work together do not experiment interoperability problems but also that the deployment has improved the global performance of the organisation concerned. Moreover, it can also be used as a guide to improve the interoperability of entities and resources within those entities.

From a semantic point of view, this method is based on a meta-model enabling a shared understanding between all people concerned with the interoperability assessment. Its strength is its design made by and for industrials, and thus thought to be easily and directly applicable in industry with the possibility to get easily automated. This method is currently tested within a helicopter manufacturer for the deployment of Systems Engineering processes. The next step in this research work is to automate this method and to couple it with process modelling activities.

\section{REFERENCES}

ATHENA (2005). Deliverable D.A1.4.1 - Framework for the establishment and management methodology. Technical report, ATHENA Project.

C4ISR (1998). Levels of information systems interoperability (LISI). Technical report, C4ISR.

Clark, T. and Jones, R. (1999). Organisational interoperability maturity model for c2. In ICCRTS 1999, United States Naval War College, Newport.

Cornu, C., Chapurlat, V., Chiavassa, B., and Irigoin, F. (2011). Mixing Systems Engineering and Enterprise Modelling principles to formalize a SE processes deployment approach in industry. In Hammami, O., Krob, D., and Voirin, J.-L., editors, CSD\&M, Paris, France, 7-9 December 2011, pages 201-210. Springer Berlin Heidelberg.

Daclin, N. (2007). Contribution au développement d' une méthodologie pour l' interopérabilité des entreprises. $\mathrm{PhD}$ thesis, Université Bordeaux 1. [in French].
Ford, T., Colombi, J., Graham, S., and Jacques, D. (2007). The interoperability score. In CSER 2007, March 14-16, Hoboken, NJ , USA.

Guédria, W., Chen, D., and Naudet, Y. (2009). A maturity model for enterprise interoperability. In R. Meersman, P. H. and Dillon, T., editors, OTM 2009 Workshops, pages 216225 .

Hamilton, J., Rosen, J., and Summers, P. (2002). An interoperability road map for C4ISR legacy systems. Technical report, DTIC Document.

Hill, J. L. (2006). A formula for calculating the index of ICT interoperability. Synthesis 2006 Journal.

IEC (2005). IEC TR 62390:2005 - Common automation device - Profile guideline.

ISO (2010). ISO/DIS 11354-1 - Advanced automation technologies and their applications - Part 1: Framework for enterprise interoperability.

Kingston, G., Fewell, S., and Richer, W. (2005). An organisational interoperability agility model. In ICCRTS 2005.

Lavean, G. E. (1980). Interoperability in defense communications. In IEEE transactions on communications, vol. Com-28, no. 9, September 1980.

Leite, M. (1998). Interoperability assessment. In 66th Military Operations Research Society Symposium. Monterey, CA, June 23-25, 1998.

NEHTA (2007). Interoperability maturity model - version 1.0. Technical report, NEHTA.

Santos, I., Schuster, S., Vergara, M., and Alonso, J. (2008). Assessing the readiness for enterprise collaboration and enterprise interoperability. In 14th International Conference on Concurrent Enterprising, Lisbon, Portugal, 23 - 25 June 2008.

Soria, I. M. D., Alonso, J., Orue-Echevarria, L., and Vergara, M. (2009). Developing an enterprise collaboration maturity model: Research challenges and future directions. In 15th International Conference on Concurrent Enterprising, Leiden, Netherlands, 22 - 24 June 2009.

Stewart, K., Clarke, H., Goillau, P., Verrall, N., and Widdowson, M. (2004). Non-technical interoperability in multinational forces. In ICCRTS 2004.

Tolk, A. and Muguira, J. A. (2003). The levels of conceptual interoperability model. In 2003 Fall Simulation Interoperability Workshop, Orlando, Florida. 